\title{
Indian Catholic Church's Response to the Elderly with Neurodegenerative and Mental Illnesses
}

\author{
H.E. Msgr. Vincent M. Concessao ${ }^{a}$, Rev. Dr. Tomi Thomas ${ }^{b}$, Anto Maliekal $^{c}$ \\ ${ }^{a}$ Emeritus Archbishop of Delhi, Bishop Responsible for Pastoral Care in Health, Catholic Bishops Conference of \\ India and Ecclesiastical Adviser, The Catholic Health Association of India \\ ${ }^{b}$ Director General, The Catholic Health Association of India \\ ${ }^{\mathrm{c}}$ Programme Manager, The Catholic Health Association of India
}

\begin{abstract}
This article provides an overview of the status of the elderly in India, especially those who suffer from neurodegenerative illnesses. It highlights how the Catholic Church in India responds to the socially and economically marginalized and vulnerable among the elderly, the emerging challenges for the elderly and those involved in geriatric care, and offers recommendations for a way forward for the Church. In spite of the commendable efforts, much needs to be done by the Church for the elderly. The Church must utilize the full potential of health care networks like the Catholic Health Association of India (CHAI) and other Faith-Based-HealthNetworks (FBHNs). Inculcating the culture of "involving all" in Christ's healing ministry, the Church in India can facilitate the building of Caring Communities to enable senior citizens to live their twilight years with dignity and peace. The Church can facilitate the democratization and decentralization of medical knowledge through task-shifting. This calls for the empowerment of local communities with information and skills to access health and health care as a fundamental right.
\end{abstract}

\section{Introduction}

By 2050, in India, due to various factors in health development, the segment of the population aged 60 years and above will surpass the population of children below 14 years. ${ }^{1}$ In absolute terms, according to the data on projected age structure of population by United Nations Department of Economic and Social Affairs (UNDESA 2008), India had more than 91.6 million elderly in 2010 with an annual addition of 2.5 million elderly between 2005 and 2010, which is projected to reach 158.7 million in 2025 . $^{2}$ The increasing number of the sick elderly suffering from neurodegenerative illnesses like dementia and mental disorders like depression is an accompanying fact. By 2050, India will have 43 million persons aged 80 or over. $^{3}$ The situation becomes significantly more challenging with rising health care costs and the facts that $80 \%$ of the elderly are in the rural areas and $30 \%$ of the elderly live below the poverty line. ${ }^{4}$ As per the Global Age Watch Index (GAWI), India ranked very poorly among the 91 countries sampled -$73^{\text {rd }}$ in the care of the elderly. ${ }^{5}$

The message of Pope Francis at the XXI Plenary Assembly of the Pontifical Council for the Family is significant in this context: "Children and the elderly are the two poles of life and also the most vulnerable, often the most forgotten. A society that abandons children and 
marginalizes the elderly severs its roots and obscures its future. Whenever a child is abandoned and an old person is marginalized, is not just an act of injustice, but it also demonstrates the failure of that society. Taking care of children and the elderly is the only choice of civilization."

This paper gives an overview of the status of the elderly in India, especially those who are affected with neurodegenerative illnesses and mental disorders. It also provides a special emphasis on the socially and economically marginalized/excluded and vulnerable (women) among the elderly; the emerging challenges for the elderly and for those involved in geriatric care; how the Catholic Church (hereafter referred to as "Church") in India responds to the situation; and finally, a way forward for the Church in India.

\section{Growth of the Elderly Population}

The National Policy on Older Persons adopted by the Government of India in January 1999 defines "senior citizen" or "elderly" as a person aged 60 years or above. Nearly $7.5 \%$ of India's population is currently aged 60 years and above. ${ }^{4}$ It is projected to rise to $12.4 \%$ of the population by the year $2026 .{ }^{7}$ By 2050 , sustaining the existing trend of the longevity of women over men, the number of elderly women would exceed the number of elderly men by 18.4 million.

\section{Health and Social Status of the}

\section{Elderly in Indian Society}

Approximately $65 \%$ of the aged have to depend on others for their day-to-day maintenance. ${ }^{2}$ Seventy percent of them are women. Nearly $40 \%$ of the elderly are still working $(60 \%$ of men and $19 \%$ of women). In urban areas, only $39 \%$ of elderly men and approximately $7 \%$ of elderly women are economically active. In rural areas, $66 \%$ of elderly men and $23 \%$ of elderly women are working. ${ }^{7}$

Based on HelpAge India, 52\% of India's Oldest Old $(80+)$ are in either poor or very poor health, and $80 \%$ were without community support. Twelve percent of the Oldest-Old are still working. ${ }^{8}$ Thirty-one percent of older persons reported facing abuse [material exploitation, financial deprivation, property grabbing, abandonment, verbal humiliation, and emotional and psychological torment $].{ }^{9}$ Most of the cases go unreported in the name of family honor, and victims are afraid of losing even the minimal support they receive.

\section{Provisions for the Support of the}

\section{Elderly}

Article 41 of the Constitution assures public assistance in old age. The enactment of the Maintenance and Welfare of Parents and Senior Citizens Act, 2007 is to ensure need-based maintenance for parents and senior citizens and for their welfare. The government, through the Central Sector Scheme of the Integrated Programme for Older Persons (IPOP), encourages PublicPrivate Partnership - supporting non-state actors to maintain/organize various facilities for the elderly. The other measures are old age pensions; income tax exemption/ deduction; travel concessions; geriatric departments in medical colleges; and establishing two National Institutes on Aging in Delhi and Chennai.

Many of these measures, however, are not fully implemented. Recently, the National Policy on Senior Citizens 2011, and in line with it, the $12^{\text {th }}$ Five Year Plan and National Mental Health Programme, placed special emphasis on senior citizens suffering from severely disabling diseases. This includes various types of dementias including Alzheimer's, Parkinson's disease, depression, and other psycho-geriatric disorders. On the whole, the country is yet to put in place measures to effectively meet the impending scenario of the growing population of the elderly, especially those suffering from neurodegenerative illnesses and mental disorders.

\section{Specific Needs Related to}

Neurodegenerative Disease and

Mental Illness 
The increased numbers of the sick elderly with neurodegenerative illnesses and various mental disorders will have a marked impact on India's infrastructures and health care systems, which are at present ill-prepared in many regions. Approximately 64 per 1,000 elderly persons in rural areas and 55 per 1,000 in urban areas suffer from one or more disabilities. ${ }^{7}$

As per the Ministry of Health and Family Welfare, one in every four among India's elderly population is depressed; one in three suffers from arthritis, while one in five cannot hear. While one in three suffers from hypertension in India, almost half have poor vision. Approximately one in ten experiences a fall that results in fracture, while two in five are anemic. ${ }^{4}$ As per HelpAge India, 30 million are lonely, and one out of eight elderly feels no one cares that they exist, and $90 \%$ have to continue to work if they have to survive. ${ }^{10}$ Eighty-eight percent said loneliness can lead to physical and mental ailments like depression. ${ }^{11}$ Many researchers believe that depression is a risk factor for dementia. There are others who argue that it is an early symptom of the disease. ${ }^{12}$ In 2010, it was estimated that there were 3.7 million affected by dementia (Alzheimer disease $[\mathrm{AD}]$ and Vascular dementia $[\mathrm{VaD}])$ in India, and the total societal cost was approximately Rs.1,470 million. People with Dementia (PwD) are expected to double by 2030 , increasing the cost by three times. ${ }^{13}$

At present, the elderly with depression and neurodegenerative illnesses are mainly taken care of by their families without much support from the public health care system, even at the primary care level. The joint family system, the traditional support system for the sick and dependent elderly people, is crumbling because of the migration of the younger generation to cities in search of better prospects. The advent of nuclear families also adds to the challenge. Women, who traditionally took on the role of caregivers, are also working and cannot spend as much time caring for the elderly. ${ }^{14}$

A neurodegenerative condition, like dementia, is considered a normal part of aging and is not perceived as requiring medical care.
Primary care physicians rarely deal with this condition in their clinical work. Private medical care is thus preferred, and this leads to a higher out-of-pocket expenditure for care. Caregivers experience significant burdens and health strain. More than $80 \%$ of caregivers are females, and approximately $50 \%$ are spouses, who are themselves quite old. Most old-age homes do not admit people with dementia. The stigma of aging, arising out of neurodegenerative illnesses like dementia, de-pression, incontinence, etc., is another social barrier to accessing health care by the elderly. People with dementia and other types of neurodegenerative illnesses and mental disorders are often neglected, ridiculed, and abused. ${ }^{14}$

The key barriers to the access to health for the Indian elderly include social barriers shaped by gender, stigma, and other axes of social inequality (religion, caste, socio-economic status). The physical barrier of reduced mobility reduces their social engagement and limits the reach of the health system. Health affordability constraints include limitations in income, employment, and assets, and the meager financial protection offered in the Indian health system. ${ }^{2}$ Social security coverage, such as employer insurance, pension scheme, etc., covers only a negligible segment of the employed population in organized sectors. The majority of the workforce is engaged either in the unorganized sector or are self-employed. They are not entitled to formal retirement benefits. As a result, a considerable proportion of the elderly is forced to earn their living by engaging in some work to manage their lives.

As $83 \%$ of health care expenses are out-ofpocket expenditures, ${ }^{2}$ the deprivation is severe and crushing for the elderly whose need for health care increases with age. Even where care is physically accessible, costs of accessing this care become beyond their reach. For the willing caregivers, especially those struggling to make both ends meet, the sick elderly become a severe economic burden. The growing comercialization of health care and the deficiencies in the public health care system also make the situation more 
complex. Among the elderly, women suffer most, especially widows (due to mobility, employment, property, and financial constraints). The predicament of elderly women is aggravated by a lifetime of gender-based discrimination. Aging women are more likely to get excluded from social security schemes due to lower literacy and awareness levels. ${ }^{15}$

\section{The Role of the Catholic Health}

\section{Association of India in Addressing the}

\section{Needs of the Elderly}

The Catholic Health Association of India (CHAI) is the largest non-government health care network in India with over 3,439 member institutions. Founded in 1943 by Sr. Dr. Mary Glowrey, an Australian nun, CHAI is one of the main arms of the Health Commission under the Bishops' Conference and comprises most of the Catholic health care facilities: 746 small, medium, and major hospitals, 2,574 health centers, 107 centers for mental health, 61 centers for alternative systems of medicine, 162 nonformal health facilities, 165 leprosy centers and 6 medical colleges, 615 residential health care centers for the aged, 678 training centers and 443 rehabilitation centers involved in the preventive and curative care of people, 123 community care centers for people living with HIV/AIDS including 40 centers for children infected/ affected, 60 counselling centers, 82 centers for tuberculosis and terminally ill (palliative care centers), 120 nursing schools/ colleges) and 600 project-based institutions focused on certain diseases in collaboration with the government, as well as engaged in other social concerns. ${ }^{161718}$

CHAI provides critical health care services to the poor and marginalized with a network of over 1,000 nun-doctors, 25,000 nun-nurses, 10,000 plus nun-paraprofessionals, and 5,000 nun social workers, along with their lay collaborators. ${ }^{17}$ One can safely assume that nearly 130,000 persons (religious, lay workers and volunteers) render services in these institutions collectively.
CHAI's member institutions treat more than 21 million per year. This includes 5,000 HIV patients, approximately 2,000 children affected or infected with HIV in institutional care, 15,000 cared for in community-based care, and 10,000 children with special needs who are provided with annual educational, health, and rehabilitation support. CHAI member institutions and their sister concerns facilitate more than two million Self Help Group members. Over 5,000 students graduate every year from CHAI-member nursing schools. ${ }^{17}$

Throughout India, in all its 615 homes for the aged, CHAI and its member institutions provide free care to nearly 18,500 elderly, who are mostly sick and abandoned by their families. However, most of these homes are located in middle-income level southern states, with nearly $40 \%$ located in the State of Kerala and the rest in Karnataka, Maharashtra, Goa, and West Bengal. ${ }^{18}$ The Church renders service to more than 60,000 elderly on a daily basis, including approximately 18,500 in its homes for the aged and 1,700 in its palliative care units. This does not include the elderly supported in its project-based institutions/ organizations and those contacted daily during home visits as part of pastoral care. Of late, serious efforts are being made to train nurses and other frontline health workers in geriatric care.

Currently, there are not many governmentrun geriatric care facilities, especially for the elderly with neurodegenerative illnesses. Some for-profit, private health care providers have recently entered the field, but are not meant to cater to the needs of the elderly from marginalized sections of the community. Further, none of them are ready to take care of the elderly with neurodegenerative and mental illnesses. It is in this space that the varied services offered by private not-for-profit faith-based-health-networks (FBHNs) like CHAI and other sister concerns in the Church become relevant. These FBHNs can make a major difference in home-based care, palliative care, etc. Recognizing the significance of FBHNs and other not-for-profit organizations, India's $12^{\text {th }}$ Five-Year Plan and the National Health Mission encourage Public Private 
Partnerships (PPP) to improve health services, including care for the elderly.

The dedicated service of the religious of FBHNs, mostly nuns, along with lay employees and experts, offers affordable quality health care. With their training and inclination for dedicated service, they form a unique cadre of health personnel who can engage in maternal and child health care, as well as the care of the elderly, terminally ill, and mentally-ill persons in a humane and dignified manner. They effectively motivate people, including those outside the faith-community, and inculcate a culture of positive health, encouraging people to adopt healthy lifestyles. The cross-linkages with Catholic Social Service Networks and School Network are also being utilized for public health activities.

\section{Task-Shifting to Address the Human}

\section{Resource Gaps in Care for the Elderly}

\section{with Neurodegenerative and Mental}

\section{IIInesses}

As is the case with any other health service, there is a severe deficiency of trained health professionals, medical practitioners as well as nurses, to take care of the elderly with neurodegenerative and mental illnesses. In this context, the concept of task-shifting is significant. Task shifting involves the rational redistribution of tasks among health workforce teams. Specific tasks are moved, where appropriate, from highly qualified health workers to health workers with lesser training and fewer qualifications, in order to make more efficient use of the available human resources for health. ${ }^{19}$ For example, breakdown of complex health care interventions into simplified, smaller, and locally-relevant components that can be transferred to and performed by the less-trained, locally available health care workers/volunteers - shifting the specific tasks from physicians to nurse practitioners and from nurses to community health workers. ${ }^{20}$ Task-shifting primarily means the capacity building of caregivers at home and local community volunteers with the basics in geriatric and palliative care, a patient-centred approach, addressing the need to give extra care and happiness for the elderly to enable them to cope with suffering, to age and die with dignity.

To lead the way in this direction, task shifting would here mean to capacitate, or upgrade the skills, of the nun-nurses, nun-paraprofessionals, lay collaborators of the Church's health care institutions, and the caregivers in providing geriatric and palliative care. Such taskshifting is needed more in medically under-/unreached areas. As noted earlier, in the midst of rising health care costs, $30 \%$ of the elderly live below the poverty line and $80 \%$ of them reside in rural areas.

Task-shifting brings down the health care costs by reducing human resource costs, thereby making quality geriatric and palliative care more accessible and affordable, especially in the underserved areas, with special focus on the elderly of the socially excluded and economically marginalized sections of society. Moreover, taskshifting, in fact, is a practical and radical example of the decentralization and democratization of medical knowledge. It empowers caregivers and health workers in the community, with supportive supervision from the professionals, to be more effective in caring for the elderly, especially those with neurodegenerative and mental illnesses, and to advocate their rights. Enabling caregivers through task-shifting to take care of the elderly echoes the Church's vision of healthcare inspired by His compassionate love, ensuring life in its fullness (Jn.10:10). ${ }^{21}$

In contrast to the growing commercialization of geriatric and palliative care, taskshifting in a Christian context encourages caregivers and local volunteers, especially the young, to be unique, to enable themselves to practice being the 'Good Samaritan' in caring for the elderly, demonstrating the compassionate care of Jesus for the marginalized and vulnerable, irrespective of caste, creed, and sex (Mt. 25:40; Lk. 9:2; Lk. 10:25-37; Acts 10:38). In contrast to the growing culture of consumerism, individualism, and the abandonment of the most vulnerable, task-shifting enables one to 
experience that "it is more blessed to give than receive" (Acts 20:35) to bear witness that all of life is a gift from God, especially in its final stage.

Task shifting calls Christians as caregivers and young volunteers to invest "hard loving" as Bishop Anthony Fisher puts it, "even with the best of care, pain and death cannot be eliminated from this life. Some problems in this life have no solution. Then comes the really hard loving: the loving of a family surrounding their comatose child, of a husband whose wife's Alzheimer's disease means she no longer recognizes him, of siblings playing patiently with their profoundly disabled brother, of a mother watching and weeping at the foot of the Cross. Sometimes the best we can do is to invest ourselves - our time, companionship, prayer, hope - in the suffering, the persistently unconscious and the dying. This is a kind of respecting and loving that no one should pretend is easy." 22

Task-shifting is thus a means to inculcate a culture of empathy among caregivers, and especially the young, local volunteers, to build them into a caring community for "the elderly who are increasingly isolated and abandoned."23 Task-shifting empowers them as Christians to declare, "Old age is not the disappearance of life but its completion ... Through solidarity between the young and the old, one has a way of understanding how the Church is really a family of all the generations, where each person must truly feel at home, where the logic of profit and possessing does not rule, but the logic of free giving and of love. When during the years of old age life becomes frail, it never loses its value or its dignity: every person is willed, is loved by God; every person is important and necessary." 24

\section{The Way Forward}

In spite of all the commendable efforts much needs to be done regarding the care of the elderly in India. The Church, under the aegis of the Catholic Bishops' Conference of India, needs to leverage the full potential of FBHNs like CHAI, and other Christian denominations and Civil Society Organizations.

\section{The Church also needs to advocate for}

1. The recognition of neurodegenerative illnesses like dementia, depression, and other mental disorders, especially affecting the elderly, as treatable under primary health care package systems in the country.

2. The availability of essential, affordable drugs for the treatment of the sick elderly with neurodegenerative illnesses and mental disorders.

3. The legalization of nurse practitioners as part of task-shifting.

\section{Other areas where the Church needs to get involved}

1. Promoting the significance of task-shifting to make care for the sick elderly and mental health care more accessible and affordable by involving Accredited Social Health Activists (ASHAs), trained birth attendants (Dais), other frontline health workers under the National Health Mission, and successful lay counselors caring for the young at risk in many organizations, etc.

2. Training and supporting the caregivers/family members to provide maximum home-based care to the elderly, especially those suffering from neurodegenerative illnesses and mental disorders.

3. Providing refresher trainings to primary care physicians to attend to the sick elderly suffering from neurodegenerative illnesses, depression, and other mental disorders.

4. Sensitizing and educating the public against stigma and discrimination of the sick elderly.

5. Creating awareness among the elderly, caregivers, and youth at the community level on the National Policy on Older Persons, legislations like "The Maintenance and Welfare of Parents and Senior Citizens Act 2007," and various schemes benefitting the elderly.

6. Promoting the utilization of modern technology, for instance, training frontline health workers in telemedicine, thereby making quality health care for the elderly 
more accessible and affordable, especially in the rural areas.

7. Promoting and undertaking research in the field of geriatric care to make it more evidence-based, accessible, and affordable for the marginalized/excluded and vulnerable among the elderly.

\section{Conclusion}

Compelled by Jesus' love and His preferential stand for the poor and marginalized, Church health institutions fulfil their obligations to continue strengthening their services for the economically underprivileged, socially excluded, and vulnerable, the elderly, children and women, while expanding to more medically underserved areas. The emerging challenges and threats from not-so-friendly external factors, be it technical/ professional, legislative, social, economic, and political, call for serious introspection. The Church has to contend with the lethargic, often corrupt, public health care systems as well as the excessively profit-minded private health care systems.

Inculcating the culture of 'involving all' in Christ's healing ministry, the Church in India has to facilitate the building of local ownership and Caring Communities that support the elderly toward healthy aging with dignity and selfrespect. This endeavor has to be shared by the elderly themselves, caregivers, local community/ religious leaders, youth, teachers, professionals, and frontline health workers/volunteers. The Church has to facilitate the democratization and decentralization of medical knowledge through task-shifting. This calls for the empowerment of local communities with information and skills to organize, demand, and access rights and entitlements from the perspective of health as a fundamental right, with a special emphasis on the elderly, children, and women.

\section{References}

1. Siva Raju S. Aging in India in the 21st Century: A Research Agenda (Priority Areas and Methodological Issues). Series I. Mumbai: The Harmony Initiative; 2006 Feb. [cited 2014 Mar 13]. Available from: http://harmonyindia.org/hdownloads/Monograph_FIN AL.pdf

2. Dey S, Nambiar D, Lakshmi JK, Sheikh K, Reddy KS. Health of the Elderly in India: Challenges of Access and Affordability. In: Smith JP, Majmundar M, editors. Aging in Asia: Findings from New and Emerging Data Initiatives. Washington, DC: The National Academies Press; 2012. p. 371-86. PubMed PMID: 23077756. [cited 2014 Mar 13]. Available from: http://www.ncbi.nlm.nih.gov/pubmed/23077756

3. UN: World Population Prospects: The 2008 Revision, Highlights. New York: United Nations; 2009. [cited 2014 Mar 13]. Available from: http://www.un.org/esa/population/publications/wpp20 08/wpp2008_highlights.pdf

4. Times News Network. India commits to improve health of elderly. The Times of India. 2012 Sep 6 [cited 2014 Mar 13]. Available from: http://articles.timesofindia.indiatimes.com/2012-0906/india/33648382_1_primary-health-care-systemmental-health-health-professionals

5. Jha DN. India ranks $73^{\text {rd }}$ in elderly care: Survey. The Times of India. 2013 Oct 2. [cited 2014 Mar 13]. Available from:

http://articles.timesofindia.indiatimes.com/2013-1002/delhi/42615003 1 health-coverage-gdp-publicspending

6. Collins C. Pope Francis: Do not abandon children, marginalize elderly. News VA [official Vatican network]. 2013 Oct 25. [cited 2014 Mar 13]. Available from: http://www.news.va/en/news/pope-francis-donot-abandon-children-marginalize-e

7. Ministry of Statistics \& Programme Implementation, Government of India. Situation Analysis of the Elderly in India. New Delhi: Government of India; 2011. [cited 2014 Mar 13]. Available from:

http://mospi.nic.in/mospi_new/upload/elderly_in_indi a.pdf

8. HelpIndiaAge:Economic and Health Survey on Ind ia's Oldest Old $(80+)$. New Delhi: HelpAge India; 2010. [cited 2014 Mar 13]. Available from: http://www.helpageindia.org/pdf/Economic-HealthSurvey-on-India's-Oldest-Old.pdf 
9. HelpAge India: Elder Abuse in India. New Delhi: HelpAge India; 2012. [cited 2014 Mar 13]. Available from: http://www.helpageindia.org/pdf/Report_ElderAbuse_India2012.pdf

10. HelpAge India: Ageing Scenario. New Delhi: HelpAge India. [cited 2014 Mar 13]. Available from: http://www.helpageindia.org/about-us/79.html

11. HelpAge India: Loneliness among Older People in India. New Delhi: Helpage India; 2008. [cited 2014 Mar 13]. Available from:

http://www.helpageindia.org/images/pdf/survey\%20\& $\%$ 20reports/Loneliness-among-Older-People-in$\underline{\text { India.pdf }}$

12. Alzheimer's Society: Am I at risk of developing dementia? London: 2014. [cited 2014 Mar 13]. Available from: http://www.alzheimers.org.uk/site/scripts/documents_i nfo.php?documentID=102

13. Alzheimer's and Related Disorders Society of India. The Dementia India Report 2010. New Delhi; 2010. [cited 2014 Mar 13]. Available from: http://www.alzheimer.org.in/assets/dementia.pdf

14. WHO. Neurological disorders: a public health approach. In: Neurological disorders: Public Health Challenges. Geneva: WHO Press; 2006. p. 41-110. [cited 2014 Apr 28]. Available from: http://www.who.int/mental_health/neurology/neurodis o/en/

15. Meijer F. The feminisation of old age. The Hindu. 2012 Oct 1. [cited 2014 Mar 13]. Available from: http://www.thehindu.com/opinion/op-ed/thefeminisation-of-old-age/article3951968.ece

16. Moras BB. Asia: Catholic Hospitals in a Challenging World. Dolentium Hominum 2013; 81(1): 114-119.

17. CHAI: Capacity Statement of CHAI. Secunderabad: The Catholic Health Association of India. [cited 2014 Mar 13]. Available from: http://chai-india.org/capacity-statement-of-chai/
18. Catholic Bishops' Conference of India (CBCI): The Catholic Directory of India 2013. Bangalore: Claretian Publications; 2013.

19. WHO. Task shifting: rational redistribution of tasks among health workforce teams. Geneva: WHO Document Production Services; 2008. [cited 2014 Mar 13]. Available from:

http://apps.who.int/iris/bitstream/10665/43821/1/9789 241596312 eng.pdf?ua $=1$

20. Patel V. Mental Health for All by Involving All [Video file]. TEDGlobal; 2012. [cited 2014 Mar 13]. Available from:

http://www.ted.com/talks/vikram_patel_mental_health for_all by involving_all

21. CBCI: Sharing the fullness of life: Health Policy of the Catholic Church in India. New Delhi: Commission of Health, CBCI; 2005.

22. McKenna B. Book Review: Catholic Bioethics for a New Millennium, Bishop Anthony Fisher OP. Catholic Women's League Australia; 2012 Mar 20. [cited 2014 Apr 23]. Available from: http://www.cwla.org.au/index.php/lastestnews/item/155-book-review-catholic-bioethics-for-anew-millennium

23. Pope Francis. Evangelii Gaudium: Apostolic Exhortation on the Proclamation of the Gospel in Today's World. Vatican City: Libreria Editrice Vaticana; 2013 Nov 24. [cited 2014 Mar 13]. Available from:

http://www.vatican.va/holy_father/francesco/apost_ex hortations/documents/papa-francesco_esortazioneap_20131124_evangelii-gaudium_en.html

24. Camilliani: The International Day of Older Persons: the Words of H.E. Msgr. Zimowski. Rome: Religiosi Camilliani; 2013 Oct 1. [cited 2014 Apr 28]. Available from:

http://www.camilliani.org/en/the-international-day-ofolder-persons-the-words-of-h-e-msgr-zimowski/

The content of this article was presented at 28th International Conference in November 2013, held in Rome organized by the Pontifical Council for Health Care Workers. It was published in CHAI E-news in Jan 2014.

Competing Interests: None declared.

Correspondence: Rev. Dr. Tomi Thomas, IMS, The Catholic Health Association of India, 157/6, Staff Road, Gunrock Enclave, Secunderabad - 500009, Andhra Pradesh, India frtomithomas@chai-india.org 
Cite this article as: Concessao VM, Thomas T, Maliekal A. Indian Catholic Church's response to the elderly with neurodegenerative and mental illnesses. Christian Journal for Global Health (August 2014), 1(1):44-52.

(C) Concessao, VM, et al. This is an open-access article distributed under the terms of the Creative Commons Attribution License, which permits unrestricted use, distribution, and reproduction in any medium, provided the original author and source are properly cited. To view a copy of the license, visit http://creativecommons.org/licenses/by/4.0/ 